\title{
Transcriptomic analysis of dystrophin RNAi knockdown reveals a central role for dystrophin in muscle differentiation and contractile apparatus organization
}

Mohammad M Ghahramani Seno ${ }^{1,2 \dagger}$, Capucine Trollet ${ }^{1 \dagger}$, Takis Athanasopoulos ${ }^{1}$, lan R Graham ${ }^{1,3}$, Pingzhao Hu², George Dickson ${ }^{1 *}$

\begin{abstract}
Background: Duchenne muscular dystrophy (DMD) is a fatal muscle wasting disorder caused by mutations in the dystrophin gene. DMD has a complex and as yet incompletely defined molecular pathophysiology hindering development of effective ameliorative approaches. Transcriptomic studies so far conducted on dystrophic cells and tissues suffer from non-specific changes and background noise due to heterogeneous comparisons and secondary pathologies. A study design in which a perfectly matched control cell population is used as reference for transcriptomic studies will give a much more specific insight into the effects of dystrophin deficiency and DMD pathophysiology.
\end{abstract}

Results: Using RNA interference (RNAi) to knock down dystrophin in myotubes from C57BL10 mice, we created a homogenous model to study the transcriptome of dystrophin-deficient myotubes. We noted significant differences in the global gene expression pattern between these myotubes and their matched control cultures. In particular, categorical analyses of the dysregulated genes demonstrated significant enrichment of molecules associated with the components of muscle cell contractile unit, ion channels, metabolic pathways and kinases. Additionally, some of the dysregulated genes could potentially explain conditions and endophenotypes associated with dystrophin deficiency, such as dysregulation of calcium homeostasis (Pvalb and Casq1), or cardiomyopathy (Obscurin, Tcap). In addition to be validated by $\mathrm{qPCR}$, our data gains another level of validity by affirmatively reproducing several independent studies conducted previously at genes and/or protein levels in vivo and in vitro.

Conclusion: Our results suggest that in striated muscles, dystrophin is involved in orchestrating proper development and organization of myofibers as contractile units, depicting a novel pathophysiology for DMD where the absence of dystrophin results in maldeveloped myofibers prone to physical stress and damage. Therefore, it becomes apparent that any gene therapy approaches for DMD should target early stages in muscle development to attain a maximum clinical benefit. With a clear and specific definition of the transcriptome of dystrophin deficiency, manipulation of identified dysregulated molecules downstream of dystrophin may lead to novel ameliorative approaches for DMD.

\section{Background}

Duchenne Muscular Dystrophy (DMD) is a progressive and fatal muscle wasting disease, which occurs in 1 of 3500 male births worldwide [1]. DMD and related

\footnotetext{
* Correspondence: G.Dickson@rhul.ac.uk

† Contributed equally

${ }^{1}$ School of Biological Sciences, Royal Holloway - University of London,
} Egham, TW20 OEX, UK animal models such as that of the $m d x$ mouse $[2,3]$ are caused by mutations in the dystrophin gene that result in absence of the largest dystrophin isoform (Dp427) from skeletal, cardiac and smooth muscles, and the CNS $[4,5]$. While studies on whole animal and cell culture models of dystrophin deficiency have allowed significant progress in unraveling the molecular pathology underlying DMD, the precise pathophysiology remains poorly 
understood [6,7]. The cytoskeletal dystrophin protein exhibits complex interactions with many other structural and signalling molecules at the muscle sarcolemma, and its absence is associated with a diverse range of molecular and cellular disturbances [8,9]. For instance, alongside the absence of dystrophin, the stability and cellular localisation of many other proteins - the so called dystrophin associated proteins (DAPs) - are perturbed. These findings all suggest a complex primary and secondary pathophysiology associated with dystrophin deficiency.

Transcriptomic studies of diseased versus normal muscles could be very informative for understanding DMD pathophysiology. A number of groups have noted differences in the gene expression patterns between dystrophic muscle tissues of DMD patients and those of dystrophin-proficient individuals, or $m d x$ compared to C57BL/6 (normal) mice [10-21]. However, studies of the direct and primary molecular sequelae of dystrophin deficiency in intact animals and tissues are complicated by secondary pathologies resulting from degenerative, regenerative, fibrotic and inflammatory changes. Cellular models of dystrophin deficiency can be complicated by non-clonal comparisons of cell lines, or by heterogeneous cellular composition (with variable myoblast, fibroblast, endothelial cell, and infiltrating blood cell content) when comparing deficient and control primary cultures. The optimum cellular model with which to evaluate the direct and primary molecular events associated with dystrophin deficiency involves a system in which expression of the protein can be manipulated experimentally in a cell autonomous manner.

RNA interference (RNAi) technology allows expression of a single gene transcript and protein product to be efficiently and specifically reduced or knocked down at the mRNA level [22]. This technique provides the opportunity to study these effects under controllable conditions, and is especially useful for multifunctional proteins such as dystrophin.

Here, we describe the specific and immediate effect of dystrophin deficiency on global gene transcription in primary muscle cell cultures in which dystrophin had efficiently been knocked down by RNAi. This approach provided the opportunity to compare the transcriptomes in dystrophin-deficient primary myotube cultures to that of their corresponding clonal cell populations, avoiding the heterogeneity routinely associated with primary cell cultures and tissue biopsies. Our results suggest that in striated myofibers, dystrophin is mainly required for proper development and organization of the contractile unit, implicating a novel pathophysiology for DMD. Genes associated with ion channels, metabolic pathways and kinases were also dysregulated in response to dystrophin deficiency. Abnormal expression of certain genes detected in our model could potentially explain conditions and endophenotypes associated with dystrophin deficiency, such as dysregulation of calcium homeostasis or cardiomyopathy.

\section{Results}

\section{Transcriptome of dystrophin-deficient myotubes}

We previously reported potent and specific knockdown of dystrophin using four different small interferring RNAs (siRNAs) [23]. Here, we used the most effective siRNA (referred to as D2) to knock down dystrophin in myotubes prepared from C57BL10 mice limb muscles. Briefly, siRNA transfections were performed at $100 \mathrm{nM}$ on days two and four post-seeding and cells were collected on day six post-seeding, forty-eight hours after induction of differentiation (see Materials \& Methods for further details). Figure 1 shows a western blot analysis of dystrophin expression in myotubes used for transcriptomic studies. This experiment showed close to zero expression of dystrophin in myotubes treated with the D2 siRNA, while this protein was well expressed both in myotubes treated with an siRNA targeting firefly GL2 luciferase (treatment control) and in untreated myotubes. No detectable change in myotube morphology was observed under phase-contrast microscopy, but immunostaining revealed an almost complete lack of dystrophin in D2 siRNA-treated myotubes (data not shown). In order to perform the transcriptomic analysis, we generated 7 biological replicates of primary myoblasts treated with the siRNA targeting dystrophin (D2), 7 biological replicates of primary myoblasts treated with the siRNA targeting luciferase (GL2, as treatment controls), and 4 replicates of untreated primary myoblasts (Untr.). The biological replicates were prepared and processed on 4 separate occasions, hence acting as independent replicates, too.

We used Illumina gene expression arrays (Mouse whole genome- 6 v1.1) to evaluate the myotubes under investigation, and analysed the data to determine the

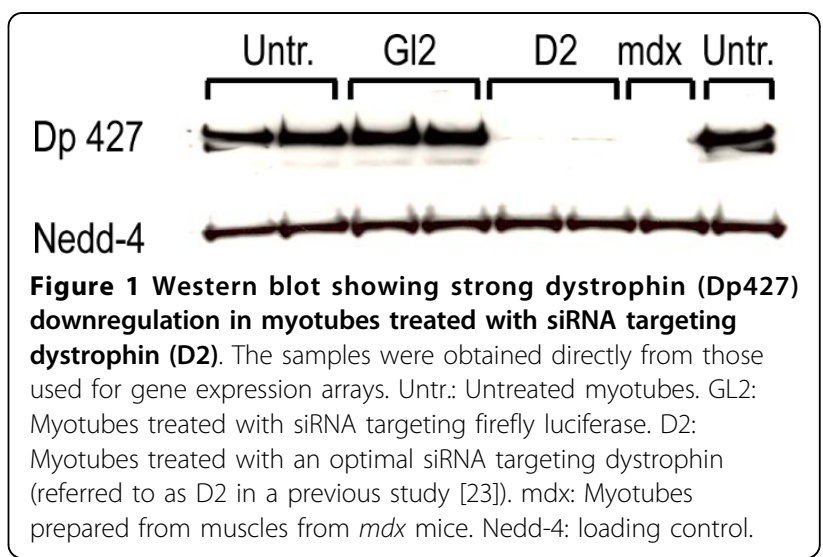


differentially expressed genes (see Materials \& Methods for details). We made two statistical comparisons: 1) global gene expression in myotubes knocked down for dystrophin compared to the untreated myotubes (list 1); and 2) global gene expression in firefly GL2 siRNA-treated myotubes compared to the untreated myotubes (list 2). By removing from list 1 the genes in common between lists 1 and 2, we created a main list of genes changed specifically by dystrophin knockdown (Additional file 1). Then we made a final list of dysregulated genes by compiling those from the main list that changed by more than 1.5 fold (with an adjusted (BenjaminiHochberg multiple testing corrected) $p$ values less than 0.05) (Additional file 2), and those that changed in both comparisons but in different directions (Additional file 2, italics; see Additional file 3 for all genes common to list 1 and 2). To confirm the array data, we performed RT-qPCR on six of the dysregulated genes. As demonstrated in Figure 2, RT-qPCR confirmed gene expression changes and corroborated the array data.

Many genes of interest with respect to skeletal muscle function or the DMD phenotype can be identified amongst the dysregulated genes displayed in Additional file 2. At first glance, several genes that have been associated with various myopathies are recognised amongst the differentially regulated genes. These include kyphoscoliosis peptidase $(K y)$ [24], cofilin 2 (Cfl2) [25,26], calpain 3 (Capn3) [27], titin-cap (Tcap) $[28,29]$ and phosphofructokinase $(P f k m)$ [30-32] (see
Table 1 for all genes from Additional file 2 cited in the text).

With respect to the significance of change, dystrophin transcript is positioned to the top of the list of significantly changing genes, only next to ribosomal protein L3-like (Rpl3l). 'CAP-GLY domain-containing linker protein family, member 4' (Clip4) and Parvalbumin $(P v a l b)$ are two other transcripts with associated $p$ values similar to that of dystrophin transcript.

Ion channels [33], metabolic pathways [34-37] and kinases-related signaling pathways [38-40] are affected in dystrophin-deficient muscle cells. Several genes of each group were dysregulated in dystrophin-deficient myotubes in our experiment. For ion channels, $S c n 1 b$ is downregulated both as reported by Pescatori et. al. [14] and in our experiments. Pescatori et. al. used muscles from children affected with DMD under the age of 2 before any overt skeletal muscle pathology - when one would expect to see a transcriptome related to dystrophin deficiency without secondary complications. Among metabolism associated molecules, 'muscle glycogen phosphorylase' (Pygm), 'phosphorylase kinase gamma 1' (Phkg1), 'phosphofructokinase, muscle' (Pfkm), 'glycerol-3-phosphate dehydrogenase 1' (Gpd1) were reproducibly downregulated in our experiment and as reported by the aforementioned group [14]. Further, despite different species being studied, we found comparable results for 'cholinergic receptor, nicotinic, epsilon polypeptide' (Chrne), 'cylin-dependent kinase

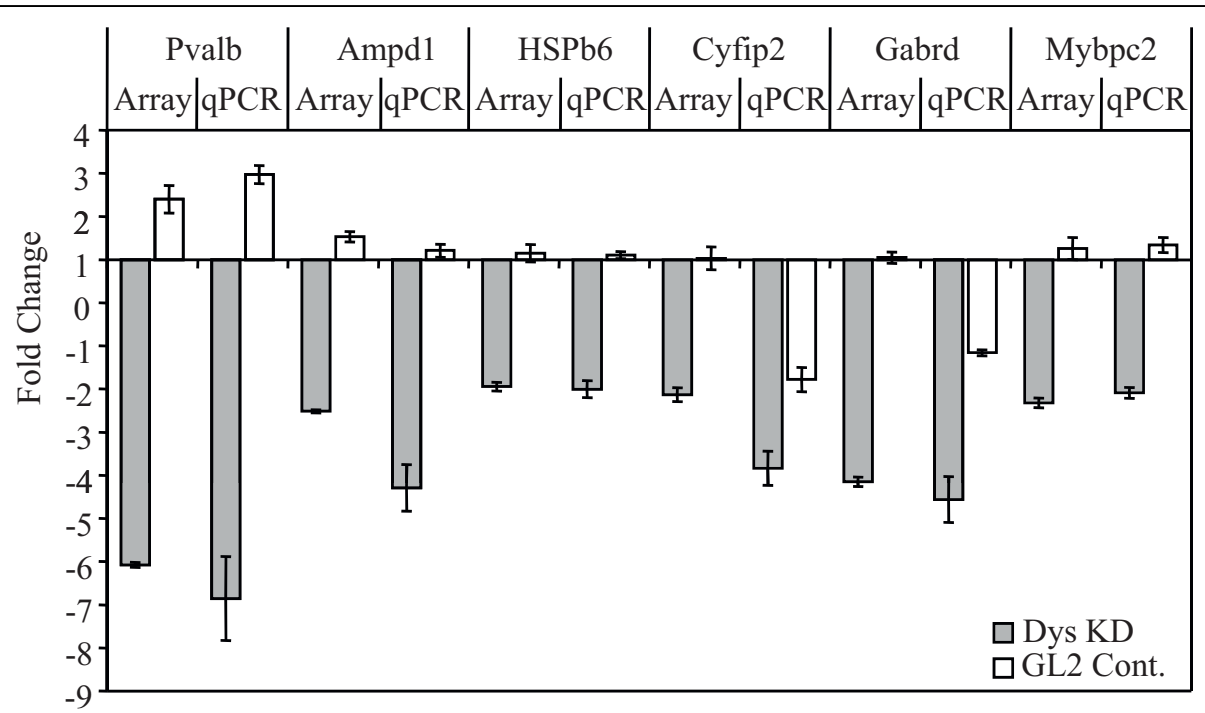

Figure 2 RT-qPCR experiment supporting expression array data. For RT-qPCR, the cDNAs made using 4 untreated biological replicates were pooled in equal amounts and used in triplicate per experiment as a reference. For each of the treatments (dystrophin knockdown (KD) or GL2 siRNA), the biological replicates from two treatment occasions (two biological replicates per each treatment occasion) were used. For each treatment occasion, the cDNAs from each biological replicate were mixed in equal amounts and used in triplicate. Relative gene expression was calculated by the $\triangle \triangle C T$ method. $Y$ axis: the normalised ratio (fold change) of expression between the treated samples (Dystrophin KD or GL2 siRNA control) versus untreated samples. Error bars indicate mean +/- 1 SD. 
Table 1 Gene differentially regulated by dystrophin deficiency and cited in the text

\begin{tabular}{|c|c|c|c|c|}
\hline Entrez ID & Gene Symbol & Gene Name & Fold Change & Adjusted $p$ value \\
\hline 66211 & Rp/3/ & ribosomal protein 13-like & -6.3 & $3.80 E-08$ \\
\hline 13405 & Dmd & dystrophin, muscular dystrophy & -3.7 & 9.54E-08 \\
\hline 19293 & Pvalb & parvalbumin & -6.1 & 9.54E-08 \\
\hline 78785 & Clip4 & CAP-GLY domain containing linker protein family, member 4 & -3 & 9.54E-08 \\
\hline 16716 & Ky & kyphoscoliosis peptidase & -4.1 & $1.48 E-07$ \\
\hline 59011 & Myoz1 & myozenin 1 & -3.6 & $2.46 E-07$ \\
\hline 19130 & Prox1 & prospero-related homeobox 1 & 3 & $2.55 \mathrm{E}-05$ \\
\hline 233199 & Mybpc2 & myosin binding protein c, fast-type & -2.3 & 3.81E-05 \\
\hline 12335 & Capn3 & calpain 3 & -2.1 & $3.82 \mathrm{E}-05$ \\
\hline 18682 & Phkgl & phosphorylase kinase gamma 1 & -3.9 & $3.82 E-05$ \\
\hline 14403 & Gabrd & gamma-aminobutyric acid (gaba-a) receptor, subunit delta & -4.2 & 8.94E-05 \\
\hline 243912 & Hspb6 & heat shock protein, alpha-crystallin-related, b6 & -1.9 & 1.77E-04 \\
\hline 140781 & Myh7 & myosin, heavy polypeptide 7 , cardiac muscle & 2.7 & $2.10 E-04$ \\
\hline 21393 & Tcap & titin-cap & -1.7 & $2.45 \mathrm{E}-04$ \\
\hline 76469 & Cmya5 & cardiomyopathy associated 5 & -1.8 & 2.74E-04 \\
\hline 380698 & Obscn & obscurin, cytoskeletal calmodulin and titin-interacting RhoGEF & -2 & 3.19E-04 \\
\hline 76884 & Cyfip2 & riken cdna 1500004i01 gene & -2.1 & 4.12E-04 \\
\hline 12632 & $\mathrm{Cfl} 2$ & cofilin 2, muscle & -1.7 & $8.51 \mathrm{E}-04$ \\
\hline 100072 & Camta1 & calmodulin binding transcription activator 1 & -1.6 & 8.96E-04 \\
\hline 20266 & Scn $1 b$ & sodium channel, voltage-gated, type i, beta & -1.7 & 9.09E-04 \\
\hline 18642 & Pfkm & phosphofructokinase, muscle & -1.5 & 1.10E-03 \\
\hline 11448 & Chrne & cholinergic receptor, nicotinic, epsilon polypeptide & -3.4 & $1.16 E-03$ \\
\hline 74769 & Pik3cb & phosphatidylinositol 3-kinase, catalytic, beta polypeptide & 1.5 & $1.25 \mathrm{E}-03$ \\
\hline 12372 & Casq1 & calsequestrin 1 & -1.6 & 3.27E-03 \\
\hline 14245 & Lpin1 & lipin 1 & -1.5 & 3.79E-03 \\
\hline 109731 & Maob & monoamine oxidase $b$ & -1.5 & 4.95E-03 \\
\hline 12575 & Cdkn1a & cyclin-dependent kinase inhibitor 1a (p21) & -1.5 & $6.65 \mathrm{E}-03$ \\
\hline 14555 & Gpd1 & glycerol-3-phosphate dehydrogenase 1 (soluble) & -1.7 & $6.65 E-03$ \\
\hline 19309 & Pygm & muscle glycogen phosphorylase & -1.6 & $7.55 E-03$ \\
\hline 26409 & Map3k7 & mitogen activated protein kinase kinase kinase 7 (Synonym Tak1) & 1.5 & $1.22 \mathrm{E}-02$ \\
\hline 338372 & Map3k9 & mitogen-activated protein kinase kinase kinase 9 & 1.8 & $1.66 \mathrm{E}-02$ \\
\hline 11474 & Actn3 & actinin alpha 3 & -1.6 & $1.75 \mathrm{E}-02$ \\
\hline 20661 & Sort1 & sortilin 1 & 1.6 & 1.82E-02 \\
\hline
\end{tabular}

This table details genes from Additional file 2 that were cited in the text. Table sorted by ascending adjusted $p$ values. Italicized genes are those dysregulated in dystrophin siRNA treated samples versus untreated samples, but changing in the opposite direction in the GL2 siRNA treated versus untreated samples (see result section for details).

inhibitor 1A' (Cdkn1a), calpain 3 (Capn3), lipin1 (Lpin1) and 'monoamine oxidase B' (Maob).

Transcripts of several kinases were dysregulated in our model; amongst them, 'mitogen-activated protein kinase kinase kinase 7' (Map3k7), 'mitogen-activated protein kinase kinase kinase 9' (Map3k9) and 'phosphatidylinositol 3-kinase, catalytic, beta polypeptide' (Pik3cb) and 'AP2-associated kinase 1 (Aak1)' all upregulated. Similarly, PI3K/Akt pathway is reported to be activated in pre-necrotic $(<2$ weeks) diaphragm and in myotubes from $m d x$ mice [38]

Heart and brain are affected in DMD, in addition to skeletal muscles. There are several genes identified in our experiment that could potentially participate in the development of heart and brain associated endophenotypes in
DMD. These genes include 'Beta myosin heavy chain' (Myh7), Obscurin (Obscn), 'heat shock protein, alphacrystalline-related B6' (Hspb6), titin (Ttn), titin-cap (Tcap), and myospryn (Cmya5) for heart associated phenotypes, and 'Cytoplasmic fragile $\mathrm{X}$ mental retardation (Fmr1) interacting protein 2' (Cyfip2), 'gamma-aminobutyric acid A receptor, delta' (Gabrd), and 'sodium channel, voltage-gated, type I, beta' (Scn1b) (Table 1) for brain associated phenotypes.

\section{Gene Ontology and Ingenuity pathway analyses}

In order to have a systematic view on gene categories altered by dystrophin deficiency, we used the tool provided by the Database for Annotation, Visualisation and Integrated Discovery (DAVID) $[41,42]$ to conduct Gene 
Ontology (GO) analysis on the genes listed in Additional file 2. As demonstrated in Table 2, a stringent approach to considering overrepresented GO terms ( $>2$ fold enrichment with adjusted $p$ values $<0.1$ ) indicated enrichment for genes involved in muscle contraction, such as those contributing to sarcomere and ion channels structures. Furthermore, a less stringent but still significant $(p<0.05)$ approach revealed overrepresentation of molecules involved in metabolic pathways and kinases (Additional file 4).

We used Ingenuity Pathway Analysis (IPA) (Ingenuity ${ }^{\circ}$ Systems, http://www.ingenuity.com) to further investigate the networks and functions possibly affected in dystrophic muscles. Among the genes in Additional file 2, IPA identified 229 network-eligible genes and suggested 14 main gene networks as being dysregulated by dystrophin deficiency (Additional file 5). Moreover, IPA discovered very significant enrichment (adjusted $p$ value $=0.0006$ ) of molecules involved in muscle contraction as well as significant enrichment (adjusted $p$ value $<0.05$ ) of other molecules involved in muscle (skeletal and cardiac) functions and disorders, metabolism of carbohydrates and neurological disorders amongst differentially expressed genes in our model (Table 3). IPA also indicated enrichment (adjusted $p$ value $<0.05)$ of genes involved in actin cytoskeletal and calcium signaling canonical pathways (Table 4).

\section{miRNAs at the dysregulated genes loci}

To evaluate possible indirect microRNA (miRNA) dysregulation by dystrophin deficiency, we investigated the

Table 2 Gene ontology (GO) analysis of differentially expressed genes listed in the Additional file 2

\begin{tabular}{|c|c|c|c|c|c|}
\hline Category & Term & Genes & $\mathrm{FE}$ & $p$ val. & $\begin{array}{l}\text { Adj. } p \\
\text { val. }\end{array}$ \\
\hline $\begin{array}{l}\text { Cellular } \\
\text { Component }\end{array}$ & $\begin{array}{l}\text { GO:0044449 contractile } \\
\text { fiber part }\end{array}$ & $\begin{array}{l}\text { OBSCN, DMN, DMD, MYBPC2, TCAP, MYH13, MYH1, LDB3, ACTN3, MYBPC3, MYH7, } \\
\text { PYGM, MYH4, TPM3, }\end{array}$ & 13.83 & $1.74 \mathrm{E}-11$ & $6.77 \mathrm{E}-09$ \\
\hline $\begin{array}{l}\text { Cellular } \\
\text { Component }\end{array}$ & GO:0030017 sarcomere & $\begin{array}{l}\text { OBSCN, DMN, DMD, MYBPC2, TCAP, MYH13, MYH1, LDB3, ACTN3, MYBPC3, MYH7, } \\
\text { PYGM, MYH4, TPM3, }\end{array}$ & 14.25 & 1.16E-11 & $9.06 \mathrm{E}-09$ \\
\hline $\begin{array}{l}\text { Cellular } \\
\text { Component }\end{array}$ & GO:0030016 myofibril & $\begin{array}{l}\text { OBSCN, DMN, DMD, MYBPC2, TCAP, MYH13, MYH1, LDB3, ACTN3, MYBPC3, MYH7, } \\
\text { PYGM, MYH4, TPM3, }\end{array}$ & 12.89 & 4.47E-11 & $1.16 \mathrm{E}-08$ \\
\hline $\begin{array}{l}\text { Cellular } \\
\text { Component }\end{array}$ & $\begin{array}{l}\text { GO:0043292 contractile } \\
\text { fiber }\end{array}$ & $\begin{array}{l}\text { OBSCN, DMN, DMD, MYBPC2, TCAP, MYH13, MYH1, LDB3, ACTN3, MYBPC3, MYH7, } \\
\text { PYGM, MYH4, TPM3, }\end{array}$ & 12.38 & 7.61E-11 & $1.48 \mathrm{E}-08$ \\
\hline $\begin{array}{l}\text { Cellular } \\
\text { Component }\end{array}$ & $\begin{array}{l}\text { GO:0005863 striated } \\
\text { muscle thick filament }\end{array}$ & MYH7, OBSCN, MYH4, MYBPC2, MYH13, MYH1, MYBPC3, & 36.18 & 1.55E-08 & $2.01 \mathrm{E}-06$ \\
\hline $\begin{array}{l}\text { Cellular } \\
\text { Component }\end{array}$ & $\begin{array}{l}\text { GO:0032982 myosin } \\
\text { filament }\end{array}$ & MYBPC? MYH13 MY & 36.18 & 1.55E-08 & $2.01 \mathrm{E}-06$ \\
\hline $\begin{array}{l}\text { Cellular } \\
\text { Component }\end{array}$ & $\begin{array}{l}\text { GO:0005859 muscle } \\
\text { myosin complex }\end{array}$ & MYH7, OBSCN, MYH4, MYBPC2, MYH13, MYH1, MYBPC3, & 33.60 & 2.67E-08 & $2.98 \mathrm{E}-06$ \\
\hline $\begin{array}{l}\text { Cellular } \\
\text { Component }\end{array}$ & $\begin{array}{l}\text { GO:0016460 myosin ॥ } \\
\text { complex }\end{array}$ & 1YH7, OBSCN, MYH4, MYBPC2, MYH13, MYH1, MYBPC3, & 29.40 & 6.95E-08 & $6.78 \mathrm{E}-06$ \\
\hline $\begin{array}{l}\text { Molecular } \\
\text { Function }\end{array}$ & $\begin{array}{l}\text { GO:0008092 } \\
\text { cytoskeletal protein } \\
\text { binding }\end{array}$ & $\begin{array}{l}\text { OBSCN, DMD, MYBPC2, MYH13, MYH1, ACTN3, EPB4.1L4B, MYBPC3, DCX, MTAP7, } \\
\text { MYH7, MYH4, MYOZ1, TMOD4, PACSIN1, PSTPIP2, TPM3, SCIN, CFL2, SPNB1, }\end{array}$ & 3.79 & 1.37E-06 & 3.63E-03 \\
\hline $\begin{array}{l}\text { Cellular } \\
\text { Component }\end{array}$ & GO:0030018 Z disc & DMN, OBSCN, PYGM, DMD, TCAP, LDB3, & 13.44 & 7.16E-05 & 5.57E-03 \\
\hline $\begin{array}{l}\text { Cellular } \\
\text { Component }\end{array}$ & GO:0031674 I band & DMN, OBSCN, PYGM, DMD, TCAP, LDB3, & 11.52 & 1.54E-04 & $1.08 \mathrm{E}-02$ \\
\hline $\begin{array}{l}\text { Cellular } \\
\text { Component }\end{array}$ & $\begin{array}{l}\text { GO:0005856 } \\
\text { cytoskeleton }\end{array}$ & $\begin{array}{l}\text { DMN, OBSCN, TTL, MYBPC2, MYH13, MYH1, ABI2, ACTN3, EPB4.1L4B, MTAP7, KRT18, } \\
\text { TMOD4, PSTPIP2, CFL2, TPM3, DYNLRB2, GAN, DMD, LDB3, MYBPC3, DCX, MYH7, } \\
\text { SGCG, KY, MYH4, MYOZ1, SCIN, SPNB1, }\end{array}$ & 2.16 & 2.14E-04 & 1.27E-02 \\
\hline $\begin{array}{l}\text { Cellular } \\
\text { Component }\end{array}$ & $\begin{array}{l}\text { GO:0016459 myosin } \\
\text { complex }\end{array}$ & MYH7, OBSCN, MYH4, MYBPC2, MYH13, MYH1, MYBPC3, & 8.11 & 2.09E-04 & 1.35E-02 \\
\hline $\begin{array}{l}\text { Biological } \\
\text { Process }\end{array}$ & $\begin{array}{l}\text { GO:0003012 muscle } \\
\text { system process }\end{array}$ & MYH7, MYH4, MYBPC2, CASQ1, KCNMA1, MYH13, MYH1, TPM3, ACTN3, MYBPC3, & 7.63 & 5.92E-06 & $1.51 \mathrm{E}-02$ \\
\hline $\begin{array}{l}\text { Biological } \\
\text { Process }\end{array}$ & $\begin{array}{l}\text { GO:0006936 muscle } \\
\text { contraction }\end{array}$ & MYH7, MYH4, MYBPC2, CASQ1, KCNMA1, MYH13, MYH1, TPM3, ACTN3, MYBPC3, & 7.63 & $5.92 \mathrm{E}-06$ & $1.51 \mathrm{E}-02$ \\
\hline $\begin{array}{l}\text { Molecular } \\
\text { Function }\end{array}$ & $\begin{array}{l}\text { GO:0031420 alkali } \\
\text { metal ion binding }\end{array}$ & $\begin{array}{l}\text { KCNC1, KCNA7, SCN3B, SCN1B, TTL, SLC9A7, ATP1B2, IMPA2, KCNMA1, KCNK3, } \\
\text { SLC24A5, GMPR, }\end{array}$ & 4.82 & 3.95E-05 & $5.10 \mathrm{E}-02$ \\
\hline $\begin{array}{l}\text { Molecular } \\
\text { Function }\end{array}$ & $\begin{array}{l}\text { GO:0030955 potassium } \\
\text { ion binding }\end{array}$ & KCNC1, KCNA7, TTL, SLC9A7, ATP1B2, KCNMA1, KCNK3, SLC24A5, GMPR, & 6.08 & 1.13E-04 & $7.22 \mathrm{E}-02$ \\
\hline $\begin{array}{l}\text { Molecular } \\
\text { Function }\end{array}$ & $\begin{array}{l}\text { GO:0003779 actin } \\
\text { binding }\end{array}$ & $\begin{array}{l}\text { DMD, MYBPC2, MYH13, MYH1, ACTN3, MYBPC3, MYH7, MYH4, TMOD4, PSTPIP2, } \\
\text { TPM3, SCIN, CFL2, SPNB1, }\end{array}$ & 3.77 & 8.93E-05 & $7.59 \mathrm{E}-02$ \\
\hline
\end{tabular}

DAVID tool was used for this analysis. Only terms with Benjamini-Hochberg adjusted $p$ values $<0.1$ and Fold Enrichment (FE) greater than 2 are displayed. Table sorted by ascending adjusted $p$ values. 
Table 3 Top functions and disorders predicted by IPA to be affected by dystrophin deficiency

\begin{tabular}{|c|c|c|}
\hline Function or Disorder & Molecules & $\begin{array}{l}\text { Adjusted } p \\
\text { value }\end{array}$ \\
\hline contraction of muscle & $\begin{array}{l}\text { ACTN3, CASQ1, CHRNE, CKMT2, EGF, GJA5, HSPB6, KCNMA1, MYBPC1, MYBPC2, MYBPC3, MYH1, MYH7, } \\
\text { MYLK2, TMOD4 }\end{array}$ & $6.33 \mathrm{E}-04$ \\
\hline atrophy of muscle cells & ACHE, FBXO32, PPARGC1A & $1.27 \mathrm{E}-02$ \\
\hline $\begin{array}{l}\text { skeletal and muscular } \\
\text { disorder }\end{array}$ & $\begin{array}{l}\text { ACHE, ACTN3, AIG1, ALKBH8, ARPP-21, BAALC, BLNK, CACNA2D1, CAMK2B, CAMTA1, CAPN3, CASQ1, } \\
\text { CDC42BPA, CDH13, CDKN1A, CENPM, CFL2, CHRNE, CLIP4, COL23A1, CYFIP2, DCLK3, DMD, DNAJB6, GABRD, } \\
\text { GAN, GIGYF2, GPD1, HTR2B, IL12A, IMPA2, IP6K3, KCNC1, KCNMA1, KCNN3, LDB3, LPIN1, MAOB, MLF1, } \\
\text { MLLT3, MYBPC1, MYH7, MYH8, MYT1L, NDRG2, NOG, PADI2, PFKM, PKD1L1, PPARGC1A, PVALB, RCSD1, } \\
\text { SCN1B, SCN3B, SERPINB1, SGCG, SORT1, SPTB, STARD10, TBC1D4, TCAP, TNRC6B, TP53BP1, TPM3, UCK2, } \\
\text { WBSCR17, WFDC1, XK }\end{array}$ & $1.46 \mathrm{E}-02$ \\
\hline cardiovascular disorder & $\begin{array}{l}\text { ABI2, ACHE, ACTN3, ARHGAP20, BLNK, CACNA2D1, CAMK2B, CAMTA1, CDC42BPA, CDH13, CDKN1A, } \\
\text { CHRNA10, CHRNE, COL23A1, CSRNP3, CYFIP2, DMD, ENTPD3, FAM65B, GABRD, GAN, GJA5, GRHL1, HERC1, } \\
\text { HSD11B1, HTR2B, IL12A, IMPA2, KCNA7, KCNC1, KCNK3, KCNMA1, KCNN3, KIAA1409, MALL (includes } \\
\text { EG:7851), MAOB, MLF1, MSI2, MYBPC1, MYBPC3, MYH7, MYH8, MYLK2, NPPB, PPARGC1A, PSTPIP2, PTPRO, } \\
\text { RCSD1, SCN1B, SGCG, SLC46A3, SLC9A2, SPTB, TBC1D4, TCAP, TNRC6B, WBSCR17, XK }\end{array}$ & 2.07E-02 \\
\hline cardiomyopathy & GJA5, HTR2B, MYBPC3, MYH7, MYLK2, NPPB, PPARGC1A, SGCG, TCAP & 2.07E-02 \\
\hline variant angina & CACNA2D1, RCSD1, SGCG & 2.07E-02 \\
\hline Huntington's disease & $\begin{array}{l}\text { ACTN3, AIG1, ARPP-21, CAMK2B, CASQ1, CYFIP2 (includes EG:26999), GABRD, GPD1, KCNN3, MAOB, MLF1, } \\
\text { MYH7, MYT1L, PFKM, PPARGC1A, PVALB, SCN1B, SCN3B, SORT1, STARD10, TPM3, UCK2 }\end{array}$ & 3.09E-02 \\
\hline disease of muscle & CHRNE, FBXO32, MYH1, MYH4, PPARGC1A, SGCG, TPM3 & 4.23E-02 \\
\hline fatigue & ACHE, CHRNE, PPARGC1A, SCN1B & 4.23E-02 \\
\hline $\begin{array}{l}\text { developmental disorder } \\
\text { of muscle }\end{array}$ & FBXO32, MYH1, MYH4, SGCG, TPM3 & 4.39E-02 \\
\hline $\begin{array}{l}\text { pervasive developmental } \\
\text { disorders }\end{array}$ & ACHE, CHRNA10, CHRNE, GABRD, HTR2B, SCN1B, SCN3B & 4.39E-02 \\
\hline deformation of nucleus & CDKN1A, MAP7 & 4.39E-02 \\
\hline $\begin{array}{l}\text { metabolism of } \\
\text { carbohydrate }\end{array}$ & $\begin{array}{l}\text { CMAH, GPD1, IMPA2, IP6K3, NISCH, PDK4, PFKM, PHKG1, PPARGC1A, PPP1R3C, PYGM, SGSH, SOCS4, } \\
\text { ST3GAL6 }\end{array}$ & 4.39E-02 \\
\hline $\begin{array}{l}\text { morphogenesis of } \\
\text { cardiac muscle }\end{array}$ & MYBPC3, MYH7, MYLK2, TCAP & 4.63E-02 \\
\hline muscular dystrophy & CAPN3, DMD, MYH7, SGCG, TCAP & 4.69E-02 \\
\hline neurological disorder & $\begin{array}{l}\text { ACHE, ACTN3, AIG1, ALKBH8, ARPP-21, BAALC, BLNK, CACNA2D1, CAMK2B, CAMTA1, CAPN3, CASQ1, } \\
\text { CATSPER4, CDC42BPA, CDH13, CHRNA10, CHRNE, CLIP4, CNKSR1, COL23A1, CYFIP2, DFNA5, DMD, DNAJB6, } \\
\text { DNAJC5, EGF, EYA3, FZD3, GABRD, GAN, GDAP1, GIGYF2, GPD1, HTR2B, IGFN1, IL12A, IMPA2, KCNC1, } \\
\text { KCNMA1, KCNN3, KIAA1409, KPNA6, LRCH1, MAOB, MLF1, MLLT3, MSI2, MT3, MYH7, MYH8, MYT1L, NDRG2, } \\
\text { OPN3, P2RY2, PADI2, PFKM, PKD1L1, PLA2G4E, PPARGC1A, PPP1R14C, PVALB, SCN1B, SCN3B, SERPINB1, } \\
\text { SGCG, SORT1, SPTB, STARD10, SUSD4, TMEM108, TPM3, TTC7B, TTLL7, UCK2, WBSCR17, WWC1, XK }\end{array}$ & 4.80E-02 \\
\hline $\begin{array}{l}\text { developmental process } \\
\text { of muscle }\end{array}$ & ACHE, CAPN3, CDKN1A, DMD, KY, MYBPC3, MYH7, MYLK2, MYOZ1, PDK4, SGCG, TCAP & 4.80E-02 \\
\hline
\end{tabular}

Genes listed in the Additional file 2 were used for this analysis. Only functions and disorders with Benjamini-Hochberg corrected $p$ values $<0.05$ are displayed.

possible presence of miRNA loci at the intronic regions of the genes displayed in Additional file 2. Table 5 details the miRNAs identified to happen at the dysregulated genes loci. miRbase miRNA data base (Sanger Inst., UK [43]) Release 12 was used for this analysis.

\section{Discussion}

Despite much effort toward disentangling the molecular basis of DMD pathophysiology, it remains unclear how the absence of one molecule results in a complicated phenotype such as DMD. This is partly due to the complexity of dystrophin interactions in muscle cells. As shown by others and in the present work, the absence of dystrophin starts a cascade of derangements in several networks. This results in underdeveloped muscles, prone to the adverse effects of physical stresses that add another level of molecular complexity to the disorder. To capture the most direct effect of

Table 4 Top predicted (by IPA) canonical pathways to be affected in dystrophin-deficient muscle cells

\begin{tabular}{lll}
\hline Canonical Pathways & Molecules & Adj $\boldsymbol{p}$ value \\
\hline Actin Cytoskeleton Signaling & MYH4, ABI2, CYFIP2, MYH8, CFL2, MYLK2, EGF, PIK3CB, MYH7, ACTN3, MYH1 & $2.45 E-02$ \\
Calcium Signaling & MYH4, TPM3, MYH8, CASQ1, CHRNE, MYH7, CHRNA10, CAMK2B, MYH1 & $3.390 E-02$ \\
\hline
\end{tabular}

Only Pathways with Benjamini-Hochberg corrected $p$ values under 0.05 are displayed. 
Table 5 Genes from Additional file 2 with miRNA loci at their intronic regions

\begin{tabular}{ll}
\hline Gene & miRNA \\
\hline Arpp21 & mmu-miR-128-2 \\
Dusp19 & mmu-miR-684-1 \\
Klf9 & mmu-miR-1192 \\
Myh7 & mmu-miR-208b \\
R3hdm1 & mmu-miR-128-1 \\
\hline
\end{tabular}

miRbase miRNA database, Release 12 was used for this analysis.

dystrophin deficiency, one has to get as close as possible to the early myogenesis stages when dystrophin naturally starts to be expressed. Having this in mind, we decided to use primary muscle cultures to study early myogenesis in the absence of dystrophin, by comparing the transcriptome of dystrophin-deficient cells to that of their normal counterparts shortly after induction of myogenesis. Similar approaches have been taken by others; however, we designed this experiment to avoid the cellular heterogeneity associated with the other studies. Accordingly, we used RNAi to knock down dystrophin in mouse primary myotubes, and compared transcriptomes in these cells to those in the same cell population but in which dystrophin had not been targeted. We have previously shown that RNAi is a robust technique for dystrophin knockdown [23]. Here, applying dystrophin RNAi to samples used for our transcriptomic studies resulted in close to zero dystrophin expression (Figure 1). We decided to analyze samples collected 48 hours after differentiation. At that time point, we did not observe any detectable change in myotube morphology or timing of fusion. We selected this early time point in order to focus on the early myogenesis events in the presence and absence of dystrophin expression, but avoid any unrelated secondary events such as myotube rupture and culture senescence. To account for possible unrelated variations, the experiment involved biological replicates prepared on four occasions (see Materials \& Methods section). This design produced meaningful results, capable of giving mechanistic insights into the conditions and endophenotypes associated with DMD.

A systematic overview of genes listed in Additional file 2 by GO and IPA analyses indicated significant overrepresentation of genes associated with the physiology of contraction, kinases, or metabolic pathways. This indicates that dystrophin is not just a molecule providing structural support to myofibers, but its presence is crucial for proper development and function of striated muscle as a contractile unit.

Other earlier studies on dystrophin deficiency support our observation that ion channels [33], kinases [38-40] and metabolic pathways [34-37] are also affected in dystrophic muscles. Here, we provide a more comprehensive view of the genes dysregulated under these categories and indicate future lines of researches to address these pathways.

\section{Dysregulated genes involved in development of skeletal muscle phenotype}

Clip4 and Pvalb had associated $p$ values similar to that of dystrophin transcript. Though not much is known about Clip4 function, Pvalb is reported to be downregulated in DMD [44] and $m d x$ [45] muscles. PVALB binds to $\mathrm{Ca}^{2+}$ and its calcium buffering capacity is important for calcium homeostasis during muscle contraction when high level of calcium is released into the sarcoplasm. Dysregulation of calcium homeostasis, with increased intracellular $\left[\mathrm{Ca}^{2+}\right]_{\mathrm{i}}$ is well documented in dystrophic muscles [46]. In line with this, Calsequestrin 1 (Casq1), the gene for CASQ1 calcium-binding protein located in sarcoplasmic reticulum (SR), was also downregulated in our model of dystrophin deficiency. Supportively, DMD muscles are reported to have deficiencies in this protein $[47,48]$. CASQ1 is believed to be essential for the normal development of the SR, and for calcium storage and regulation inside SR [49].

Kinases can initiate long range signaling activity by activating transcription factors that in turn will activate transcription of their target genes. One way for kinases to specify their local activity is by being targeted and anchored to the region where their activity is required [50]. A single molecule such as dystrophin could regulate the expression of a variety of myogenesis-related genes through its role in anchoring other molecules in the right locale. This property can help localise kinases and/or other signaling molecules to where their functions are required for proper myogenesis. For instance, dystrobrevin [51] and synemin [52], two dystrophin associated proteins [53,54], act to localise protein kinase A (PKA). Myospryn (Cmya5), a gene downregulated in dystrophin-deficient myotubes in our model, has binding sites for PKA, anchoring it at the costamere to localise PKA signaling at this complex region [55]. Supportively, it has been documented that dystrophin deficiency results in downregulation $[19,40]$ and mislocalisation of myospryn in skeletal muscles, resulting in lower PKA activity [40]. Nearly two thirds of the genes dysregulated in our experiments were downregulated (220 of 333, Additional file 2) indicating possible under-activity of certain myogensis-related transcription factors normally activated by kinases. In fact, dysregulation of some transcription factors in $m d x$ skeletal muscle has already been reported [56].

Our results also suggest that myofiber type fate determination may be affected by dystrophin deficiency. Upregulation of 'prospero-related homeobox 1' (Prox1) 
is a key step in formation of slow muscle fibres [57]. Our samples in which dystrophin had been downregulated showed three-fold increase in Prox1. Additionally, 'Fast type myosin binding protein c' (Mybpc2) and 'alpha actinin3' (Actn3) were downregulated in dystrophin deficient myotubes in our experiment. Actn3 levels increase in accord with increases in skeletal muscle fast fibers [58]; and specific expression of $M y b p c 2$ in fast fibre muscles has also been documented [59].

\section{Dysregulated genes involved in development of heart phenotype}

Heart is another organ which is involved by the pathogenesis of dystrophin deficiency. There are several molecules identified by our model that can potentially explain the mechanism(s) by which heart is adversely affected in DMD. For instance, obscurin, which was downregulated in our experiment, is required for proper assembly of M-band and A-band and myofibrillar clusters and for the regular alignment of the SR network around the contractile apparatus [60,61]. Hspb6, which associates with actin, is a cardioprotector under stressful conditions [62] and its mRNA was downregulated in association with dystrophin deficiency in this experiment.

Z-disc and costamere and their associated molecules function as mechanosensors in striated muscles, and their perturbation can result in architectural distortion of the affected muscle cells [63]. Hence, mutations in some genes involved in this area, such as titin and titincap, can result in cardiomyopathy [64,65]. Titin-cap was downregulated in dystrophin-deficient myotubes in our experiment, as was myozenin 1, another Z-disc associated protein.

Expression of the myospryn gene was downregulated by dystrophin deficiency in our model. It is also downregulated in both DMD [19] and $m d x$ [40]; and single nucleotide polymorphisms at the myospryn locus are associated with ventricular hypertrophy [66]. This gene is expressed exclusively in heart and skeletal muscle during embryogenesis and in adult striated muscle [67]. Interestingly, as it was mentioned earlier myospryn protein is a docking molecule for protein kinase $\mathrm{A}$ at the costamere, and involved in localising and specifying signal transduction at this region [40].

\section{Conclusion}

Our work depicts a specific transcriptome associated with dystrophin deficiency, with minimal noise from non-specific complications such as non-clonal cells or biopsy-associated issues such as necrosis/degeneration/ regeneration. While our results are affirmatively reproducing several previous in vitro and in vivo experiments, indicating the soundness of the data, they additionally suggest that dystrophin may be crucial for proper development of striated muscles as an organized contractile unit, implicating a novel pathophysiology for DMD. Dysregulation of several molecules converging at functions associated with the contractile unit of the myofibers is indicative of an aberrant myogenesis process resulting in maldeveloped myofibers which may be susceptible to physical or cytotoxic stress. Future experiments should include time course studies to identify longer-term sequelae of dystrophin deficiency. These data complement our previous in vivo work with dystrophin shRNAs expressed from AAV vectors [23], which suggested that the presence of dystrophin is not as essential after striated muscles have fully developed. Accordingly, transient gene therapy or other approaches to counter dystrophin-deficiency at early stages of skeletal muscle maturation might confer long lasting therapeutic benefit. In addition, the identification of dysregulated genes linked to dystrophin deficiency will provide insights and experimental approaches to define novel therapeutic targets for the potential treatment of DMD.

\section{Methods}

\section{Cell culture \& siRNA transfection}

Primary muscle cultures were prepared from limb muscles of 3 to 5 day old mice, as described previously [68]. Seven biological replicates of primary myoblasts treated with the siRNA targeting dystrophin, or the siRNA targeting GL2 luciferase (as treatment controls), and 4 replicates of untreated primary myoblasts were prepared on four occasions. In order to have a uniform cell population between replicates at each instance, the muscle cell homogenates from different mice were mixed well and the resulting cell mixture was used to prepare the cultures. The cells were seeded in $150 \mathrm{~cm}^{2}$ tissue culture plates and one animal per plate was used. After approximately 48 hours, the cultures were about $60 \%$ confluent and were subjected to the first transfection with siRNAs. The siRNA targeting dystrophin had been designed using an algorithm developed by Cenix BioScience GmbH (Dresden, Germany) and manufactured by Ambion (Austin, USA) (see [23] for more details). The control siRNA targeting firefly GL2 luciferase was ordered from Dharmacon (Lafayette, USA). siRNAs were introduced into the primary muscle cultures at a final concentration of $100 \mathrm{nM}$ using Oligofectamine transfection reagent (Invitrogen, Paisley, UK), following the manufacturer's instructions. Briefly, at the time of transfection, media were replaced with $13.5 \mathrm{ml}$ per plate of complete DMEM supplemented with $10 \%$ serum. To transfect the cells in each plate $45 \mu$ l oligofectamine was gently diluted in $105 \mu$ l OptiMEM (Invitrogen) and incubated at room temperature for 10 minutes. The oligofectamine preparation was then added to $75 \mu \mathrm{l}$ 
$(20 \mu \mathrm{M})$ oligonucleotide already diluted in $1275 \mu \mathrm{l}$ of OpiMEM, mixed gently and incubated for 20 minutes at room temperature before adding to the plates. 7 hours after transfection $15 \mathrm{ml}$ of complete DMEM supplemented with $20 \%$ serum was added to each plate. 96 hours after seeding, when cultures were fully confluent, media were changed to serum-free Dulbecco's Minimal Essential Medium (DMEM) to induce differentiation of myoblasts, and a second transfection was performed at this time in serum free media as explained above. Cells were harvested for protein and total RNA assays 48 hours after the second transfection.

\section{RNA isolation}

Total RNA was extracted using PARIS kit (Ambion) according to the manufacturer recommended protocol. The quality of RNAs was checked using Agilent Bioanalyser (Santa Clara, USA). RNAs were stored at $-80^{\circ} \mathrm{C}$ until used.

\section{Antibodies}

We used the following antibodies in this experiment: mouse monoclonal antibody NCL-DYS2 detecting the C-terminus of dystrophin (Clone Dy8/6C5; Novocastra Laboratories, UK), Nedd-4 mouse monoclonal antibody detecting Nedd-4 (Transduction Laboratories, USA) and Goat anti-mouse HRP-secondary antibody (Jackson ImmunoResearch Laboratories, USA).

\section{Western Blotting}

Protein extracts were obtained by using a small portion of the same cell samples lysed for RNA isolation using a PARIS kit (Ambion) as instructed by the manual. The cell lysates were added with equal volumes of $2 \times$ lysis buffer. $1 \times$ lysis buffer contained $75 \mathrm{mM}$ Tris- $\mathrm{HCl}$ (Sigma-Aldrich, UK) pH 6.8; 10\% SDS (Sigma-Aldrich); $20 \%$ Glycerol (Sigma-Aldrich); $200 \mathrm{mg} / \mathrm{ml}$ EDTA (Sigma-Aldrich) and $20 \mu \mathrm{g} / \mathrm{ml}$ phenylmethylsulfonyl fluoride (Sigma-Aldrich). Cell lystes were then passed through a 25 gauge hypodermic needle several times to shear DNA and hence reduce viscosity. DTT (Dithiothreitol, Sigma-Aldrich) and bromophenol blue were excluded from the buffer in this stage as they interfered with protein assay. To determine the total protein amount in samples, the BCA protein assay kit and protocol (Perbio Science, UK) was used. Twenty micrograms of each of the samples was run on Tris-Acetate 3-8\% NuPAGE gels (Invitrogen) using Tris-acetate SDS running buffer (Invitrogen) for dystrophin detection.

\section{RNA amplification and Illumina expression array chip hybridisation}

The RNA amplification, chip hybridization and data extraction was done as a service by The Centre for
Applied Genomics, Toronto, Canada. Illumina MouseWG-6_V1_1 gene expression arrays (San Diego, USA) were used for global gene expression studies. $250 \mathrm{ng}$ total RNA was used to make amplified cRNAs using Illumina TotalPrep RNA amplification kit (Ambion). $1.5 \mu \mathrm{g}$ cRNA was then hybridized to each microarray chip following manufacturer instructions. The signals were detected and gathered using BeadArray Reader (Illumina). The data were then uploaded to Bead Studio software (Illumina) and after qualitative evaluation, the text file data were extracted and statistically analyzed as explained below. Gene expression data have been deposited in Gene Expression Omnibus (GEO) http://www. ncbi.nlm.nih.gov/geo/index.cgi with the assigned GEO accession number GSE20548.

\section{Statistical analysis}

Background correction was made as described by Irizarry et al. [69]. The background corrected data were then transformed into $\log 2$ scales, and quantile normalisation was performed between arrays as previously described [70]. The three-step normalisation procedure was carried out using the Lumi software package for the $\mathrm{R}$ programming environment [71]. To assess differential gene expression, LIMMA (linear models for microarray data) method [72] was used. $p$ values were adjusted for multiple testing using the Benjamini and Hochberg method.

\section{RT-qPCR and primers}

RNA samples were first treated with DNase I (Qiagen, Germany) as instructed by the manufacturer to remove possible DNA contaminations. $1 \mu \mathrm{g}$ total RNA was then reverse transcribed using the Supercript III reverse transcription kit (Invitrogen) following manufacturer instructions. 1-2 ul of 1:5 diluted cDNA were used for quantitative PCR reaction using Brilliant II fast SYBR Green qPCR master mix (Agilent Technologies) in a total of $15 \mu \mathrm{L}$ reaction volume. PCR reaction was carried out as follows: 10 minutes at $95^{\circ} \mathrm{C}$ followed by 40 cycles at $95^{\circ} \mathrm{C}$ for $20 \mathrm{~s}$ and $60^{\circ} \mathrm{C}$ for $60 \mathrm{~s}$. Specificity of the PCR product was checked by melting-curve analysis using the following program: $55^{\circ} \mathrm{C}$ increasing $0.5^{\circ} \mathrm{C}$ in 60 steps, each step was $10 \mathrm{~s}$ temperature. Expression levels were calculated according to the $\Delta \Delta \mathrm{Ct}$ method normalised to the Elval1 mRNA expression. The Elval1 gene was used as an internal normaliser, as it showed the least variation (based on our microarray data) among all different replicates and conditions.

RT-qPCR primers were designed at exon-exon boundaries using Primer 3 software [73], unless mentioned otherwise (Additional file 6). The primers were initially tested by running an end-point PCR for each using SybrGreen master mix. The products were run on 
agarose gel for the product size as well as being used to perform melting curve analysis.

\section{Animal husbandry}

Animals were bred in-house and food and water provided ad libitum. They were maintained, and experimentation conducted under statutory Home Office recommendation, regulatory, ethical and licensing procedures and under the Animals (Scientific Procedures) Act 1986 (PPL 70/6160).

Additional file 1: A table listing genes initially prepared from genes
changing by dystrophin deficiency.
Additional file 2: A table listing all genes changing by dystrophin
deficiency that was used for further GO and IPA analyses.
Additional file 3: A table listing changing genes common to
"dystrophin siRNA treated versus untreated samples" and "GL2
siRNA treated versus untreated samples" comparisons.
Additional file 4: A table listing enriched GO terms amongst genes
changing by dystrophin deficiency.
Additional file 5: A table listing predicted networks by IPA to be
dysregulated by dystrophin deficiency.
Additional file 6: A table listing primers used for RT-qPCR.

\section{Abbreviations}

DMD: Duchenne muscular dystrophy; RNAi: RNA interference; siRNA: small interfering RNA; IPA: Ingenuity Pathway Analysis; DAVID: Database for Annotation, Visualization and Integrated Discovery; PKA: protein kinase A.

\section{Acknowledgements}

We would like to thank Mr. Jeff McDonald for kindly helping with the identification of miRNAs happening at dysregulated gene loci and also Dr. Janet Buchanan for kindly reading critically and editing the manuscript; and also her very helpful comments/advice. This research work was supported by funds from the Muscular Dystrophy Campaign, UK, the Association Française contre les Myopathies (AFM) and the EU Clinigene Network of Excellence. MMGS was a recipient of a scholarship from Ministry of Science, Research and Technology, Iran.

\section{Author details}

${ }^{1}$ School of Biological Sciences, Royal Holloway - University of London, Egham, TW20 OEX, UK. ${ }^{2}$ The Centre for Applied Genomics, Hospital for Sick Children, Toronto, M5G 1L7, Canada. ${ }^{3}$ Wellcome Trust Sanger Institute, Wellcome Trust Genome Campus, Hinxton, Cambridge, CB10 1SA, UK.

\section{Authors' contributions}

GD and MMGS designed the experiment. MMGS made primary cell cultures, performed RNAi, prepared the RNA, conducted GRT-PCR and performed GO and IPA analyses. CT helped with RNA and RT-qPCR data preparations. IRG helped with the cell culture and western blot experiment. TA helped with RNAi. PH performed statistical analysis of microarray data. GD, MMGS, CT, $\mathrm{TA}$ and $\mathrm{PH}$ wrote the paper. All authors read and approved the final manuscript.

Received: 6 January 2010 Accepted: 1 June 2010 Published: 1 June 2010

\section{References}

1. Emery AEH: Duchenne Muscular Dystrophy. Oxford Monographs on Medical Genetics. Oxford, UK: Oxford Univ. Press, 21993.

2. Bulfield G, Siller WG, Wight PA, Moore KJ: X chromosome-linked muscular dystrophy (mdx) in the mouse. Proc Natl Acad Sci USA 1984, 81(4):1189-1192.
3. Sicinski P, Geng Y, Ryder-Cook AS, Barnard EA, Darlison MG, Barnard PJ: The molecular basis of muscular dystrophy in the mdx mouse: a point mutation. Science 1989, 244(4912):1578-1580.

4. Hoffman EP, Brown RH Jr, Kunkel LM: Dystrophin: the protein product of the Duchenne muscular dystrophy locus. Cell 1987, 51(6):919-928.

5. Muntoni F, Torelli S, Ferlini A: Dystrophin and mutations: one gene, several proteins, multiple phenotypes. Lancet Neurol 2003, 2(12):731-740.

6. Deconinck N, Dan B: Pathophysiology of duchenne muscular dystrophy: current hypotheses. Pediatr Neurol 2007, 36(1):1-7.

7. Niebroj-Dobosz I, Fidzianska A, Hausmanowa-Petrusewicz I: Controversies about the function of dystrophin in muscle. Folia Neuropathol 2001, 39(4):253-258.

8. Blake DJ, Weir A, Newey SE, Davies KE: Function and genetics of dystrophin and dystrophin-related proteins in muscle. Physiol Rev 2002, 82(2):291-329.

9. Lapidos KA, Kakkar R, McNally EM: The dystrophin glycoprotein complex: signaling strength and integrity for the sarcolemma. Circ Res 2004, 94(8):1023-1031.

10. Boer JM, de Meijer EJ, Mank EM, van Ommen GB, Den Dunnen JT: Expression profiling in stably regenerating skeletal muscle of dystrophin-deficient mdx mice. Neuromuscul Disord 2002, 12(Suppl 1): S118-S124.

11. Chen YW, Zhao P, Borup R, Hoffman EP: Expression profiling in the muscular dystrophies: identification of novel aspects of molecular pathophysiology. J Cell Biol 2000, 151(6):1321-1336.

12. Haslett JN, Sanoudou D, Kho AT, Han M, Bennett RR, Kohane IS, Beggs AH Kunkel LM: Gene expression profiling of Duchenne muscular dystrophy skeletal muscle. Neurogenetics 2003, 4(4):163-171.

13. Noguchi S, Tsukahara T, Fujita M, Kurokawa R, Tachikawa M, Toda T, Tsujimoto A, Arahata K, Nishino I: cDNA microarray analysis of individual Duchenne muscular dystrophy patients. Hum Mol Genet 2003, 12(6):595-600.

14. Pescatori M, Broccolini A, Minetti C, Bertini E, Bruno C, D'Amico A, Bernardini C, Mirabella M, Silvestri G, Giglio V, et al: Gene expression profiling in the early phases of DMD: a constant molecular signature characterizes DMD muscle from early postnatal life throughout disease progression. FASEB J 2007, 21(4):1210-1226.

15. Porter JD, Khanna S, Kaminski HJ, Rao JS, Merriam AP, Richmonds CR, Leahy P, Li J, Guo W, Andrade FH: A chronic inflammatory response dominates the skeletal muscle molecular signature in dystrophindeficient mdx mice. Hum Mol Genet 2002, 11(3):263-272.

16. Porter JD, Merriam AP, Leahy P, Gong B, Khanna S: Dissection of temporal gene expression signatures of affected and spared muscle groups in dystrophin-deficient (mdx) mice. Hum Mol Genet 2003, 12(15):1813-1821.

17. Rouger K, Le Cunff M, Steenman M, Potier MC, Gibelin N, Dechesne CA, Leger JJ: Global/temporal gene expression in diaphragm and hindlimb muscles of dystrophin-deficient (mdx) mice. Am J Physiol Cell Physiol 2002, 283(3):C773-C784

18. Tkatchenko AV, Le Cam G, Leger JJ, Dechesne CA: Large-scale analysis of differential gene expression in the hindlimb muscles and diaphragm of mdx mouse. Biochim Biophys Acta 2000, 1500(1):17-30.

19. Tkatchenko AV, Pietu G, Cros N, Gannoun-Zaki L, Auffray C, Leger JJ, Dechesne CA: Identification of altered gene expression in skeletal muscles from Duchenne muscular dystrophy patients. Neuromuscul Disord 2001, 11(3):269-277.

20. Tseng BS, Zhao P, Pattison JS, Gordon SE, Granchelli JA, Madsen RW, Folk LC, Hoffman EP, Booth FW: Regenerated mdx mouse skeletal muscle shows differential mRNA expression. J Appl Physiol 2002, 93(2):537-545

21. Turk R, Sterrenburg E, de Meijer EJ, van Ommen GJ, Den Dunnen JT, t Hoen PA: Muscle regeneration in dystrophin-deficient mdx mice studied by gene expression profiling. BMC Genomics 2005, 6:98,

22. Rao M, Sockanathan S: Molecular mechanisms of RNAi: implications for development and disease. Birth Defects Res CEmbryo Today 2005, 75(1):28-42.

23. Ghahramani Seno MM, Graham IR, Athanasopoulos T, Trollet $C$, Pohlschmidt M, Crompton MR, Dickson G: RNAi-mediated knockdown of dystrophin expression in adult mice does not lead to overt muscular dystrophy pathology. Hum Mol Genet 2008, 17(17):2622-2632.

24. Blanco G, Coulton GR, Biggin A, Grainge C, Moss J, Barrett M, Berquin A, Marechal G, Skynner M, van Mier P, et al: The kyphoscoliosis (ky) mouse is 
deficient in hypertrophic responses and is caused by a mutation in a novel muscle-specific protein. Hum Mol Genet 2001, 10(1):9-16.

25. Agrawal PB, Greenleaf RS, Tomczak KK, Lehtokari VL, Wallgren-Pettersson C, Wallefeld W, Laing NG, Darras BT, Maciver SK, Dormitzer PR, et al: Nemaline myopathy with minicores caused by mutation of the CFL2 gene encoding the skeletal muscle actin-binding protein, cofilin-2. Am J Hum Genet 2007, 80(1):162-167.

26. Thirion C, Stucka R, Mendel B, Gruhler A, Jaksch M, Nowak K, Binz N, Laing NG, Lochmuller $\mathrm{H}$ : Characterization of human muscle type cofilin (CFL2) in normal and regenerating muscle. Eur J Biochem 2001, 268(12):3473-3482

27. Richard I, Broux O, Allamand V, Fougerousse F, Chiannilkulchai N, Bourg N, Brenguier L, Devaud C, Pasturaud P, Roudaut C: Mutations in the proteolytic enzyme calpain 3 cause limb-girdle muscular dystrophy type 2A. Cell 1995, 81(1):27-40.

28. Moreira ES, Vainzof M, Marie SK, Sertie AL, Zatz M, Passos-Bueno MR: The seventh form of autosomal recessive limb-girdle muscular dystrophy is mapped to 17q11-12. Am J Hum Genet 1997, 61(1):151-159.

29. Moreira ES, Wiltshire TJ, Faulkner G, Nilforoushan A, Vainzof M, Suzuki OT, Valle G, Reeves R, Zatz M, Passos-Bueno MR, et al: Limb-girdle muscular dystrophy type $2 \mathrm{G}$ is caused by mutations in the gene encoding the sarcomeric protein telethonin. Nat Genet 2000, 24(2):163-166.

30. Nakajima H, Kono N, Yamasaki T, Hotta K, Kawachi M, Kuwajima M, Noguchi T, Tanaka T, Tarui S: Genetic defect in muscle phosphofructokinase deficiency. Abnormal splicing of the muscle phosphofructokinase gene due to a point mutation at the $5^{\prime}$-splice site. J Biol Chem 1990, 265(16):9392-9395.

31. Raben N, Sherman JB: Mutations in muscle phosphofructokinase gene. Hum Mutat 1995, 6(1):1-6.

32. Tarui S, Ikura Y, Tanaka T, Suda M, Nishikawa M: Phosphofructokinase deficiency in skeletal muscle. A new type of glycogenesis. Biochem Biophys Res Commun 1965, 19:517-523.

33. Allard B: Sarcolemmal ion channels in dystrophin-deficient skeletal muscle fibres. J Muscle Res Cell Motil 2006, 27(5-7):367-373.

34. Chinet AE, Even PC, Decrouy A: Dystrophin-dependent efficiency of metabolic pathways in mouse skeletal muscles. Experientia 1994, 50(6):602-605.

35. Khairallah M, Khairallah R, Young ME, Dyck JR, Petrof BJ, Des RC: Metabolic and signaling alterations in dystrophin-deficient hearts precede overt cardiomyopathy. J Mol Cell Cardiol 2007, 43(2):119-129.

36. McClure WC, Rabon RE, Ogawa H, Tseng BS: Upregulation of the creatine synthetic pathway in skeletal muscles of mature mdx mice. Neuromuscul Disord 2007, 17(8):639-650.

37. Zhang W, ten Hove M, Schneider JE, Stuckey DJ, Sebag-Montefiore L, Bia BL, Radda GK, Davies KE, Neubauer S, Clarke K: Abnormal cardiac morphology, function and energy metabolism in the dystrophic $\mathrm{mdx}$ mouse: an MRI and MRS study. J Mol Cell Cardiol 2008, 45(6):754-760.

38. Dogra C, Changotra H, Wergedal JE, Kumar A: Regulation of phosphatidylinositol 3-kinase (PI3K)/Akt and nuclear factor-kappa B signaling pathways in dystrophin-deficient skeletal muscle in response to mechanical stretch. J Cell Physiol 2006, 208(3):575-585.

39. Kumar A, Khandelwal N, Malya R, Reid MB, Boriek AM: Loss of dystrophin causes aberrant mechanotransduction in skeletal muscle fibers. FASEB $J$ 2004, 18(1):102-113.

40. Reynolds JG, McCalmon SA, Donaghey JA, Naya FJ: Deregulated protein kinase A signaling and myospryn expression in muscular dystrophy. J Biol Chem 2008, 283(13):8070-8074.

41. Dennis G Jr, Sherman BT, Hosack DA, Yang J, Gao W, Lane HC, Lempicki RA: DAVID: Database for Annotation, Visualization, and Integrated Discovery. Genome Biol 2003, 4(5):3.

42. Huang dW, Sherman BT, Lempicki RA: Systematic and integrative analysis of large gene lists using DAVID bioinformatics resources. Nat Protoc 2009, 4(1):44-57.

43. Griffiths-Jones $S$, Saini HK, van Dongen S, Enright AJ: miRBase: tools for microRNA genomics. Nucleic Acids Res 2008, 36 Database: D154-D158,

44. Niebroj-Dobosz I, Lukasiuk M: Immunoblot analysis of sarcoplasmic calcium binding proteins in Duchenne muscular dystrophy. I Neurol 1995, 242(2):82-86.

45. Sano M, Yokota T, Endo T, Tsukagoshi H: A developmental change in the content of parvalbumin in normal and dystrophic mouse (mdx) muscle. J Neurol Sci 1990, 97(2-3):261-272.
46. Hopf FW, Turner PR, Steinhardt RA: Calcium misregulation and the pathogenesis of muscular dystrophy. Subcell Biochem 2007, 45:429-464

47. Lucas-Heron B: Muscular degeneration in Duchenne's dystrophy may be caused by a mitochondrial defect. Med Hypotheses 1995, 44(4):298-300.

48. Lucas-Heron B: Absence of a calmitine-specific protease inhibitor in skeletal muscle mitochondria of patients with Duchenne's muscular dystrophy. Biochem Biophys Res Commun 1996, 225(3):701-704.

49. Paolini C, Quarta M, Nori A, Boncompagni S, Canato M, Volpe P, Allen PD, Reggiani C, Protasi F: Reorganized stores and impaired calcium handling in skeletal muscle of mice lacking calsequestrin-1. J Physiol 2007, 583(Pt 2):767-784.

50. Wong W, Scott JD: AKAP signalling complexes: focal points in space and time. Nat Rev Mol Cell Biol 2004, 5(12):959-970.

51. Ceccarini M, Grasso M, Veroni C, Gambara G, Artegiani B, Macchia G, Ramoni C, Torreri P, Mallozzi C, Petrucci TC, et al: Association of dystrobrevin and regulatory subunit of protein kinase A: a new role for dystrobrevin as a scaffold for signaling proteins. J Mol Biol 2007, 371(5):1174-1187.

52. Russell MA, Lund LM, Haber R, McKeegan K, Cianciola N, Bond M: The intermediate filament protein, synemin, is an AKAP in the heart. Arch Biochem Biophys 2006, 456(2):204-215.

53. Bhosle RC, Michele DE, Campbell KP, Li Z, Robson RM: Interactions of intermediate filament protein synemin with dystrophin and utrophin. Biochem Biophys Res Commun 2006, 346(3):768-777.

54. Sadoulet-Puccio HM, Rajala M, Kunkel LM: Dystrobrevin and dystrophin: an interaction through coiled-coil motifs. Proc Natl Acad Sci USA 1997, 94(23):12413-12418.

55. Reynolds JG, McCalmon SA, Tomczyk T, Naya FJ: Identification and mapping of protein kinase $\mathrm{A}$ binding sites in the costameric protein myospryn. Biochim Biophys Acta 2007, 1773(6):891-902.

56. Dogra C, Srivastava DS, Kumar A: Protein-DNA array-based identification of transcription factor activities differentially regulated in skeletal muscle of normal and dystrophin-deficient $\mathrm{mdx}$ mice. Mol Cell Biochem 2008, 312(1-2):17-24.

57. Roy S, Wolff $C$, Ingham PW: The u-boot mutation identifies a Hedgehogregulated myogenic switch for fiber-type diversification in the zebrafish embryo. Genes Dev 2001, 15(12):1563-1576.

58. Ogura $Y$, Naito H, Kakigi R, Ichinoseki-Sekine N, Kurosaka M, Katamoto S: Alpha-actinin-3 levels increase concomitantly with fast fibers in rat soleus muscle. Biochem Biophys Res Commun 2008, 372(4):584-588.

59. Kurasawa M, Sato N, Matsuda A, Koshida S, Totsuka T, Obinata T: Differential expression of C-protein isoforms in developing and degenerating mouse striated muscles. Muscle Nerve 1999, 22(2):196-207.

60. Borisov AB, Sutter SB, Kontrogianni-Konstantopoulos A, Bloch RJ, Westfall MV, Russell MW: Essential role of obscurin in cardiac myofibrillogenesis and hypertrophic response: evidence from small interfering RNA-mediated gene silencing. Histochem Cell Biol 2006, 125(3):227-238.

61. Kontrogianni-Konstantopoulos $A$, Catino DH, Strong JC, Sutter S, Borisov AB, Pumplin DW, Russell MW, Bloch RJ: Obscurin modulates the assembly and organization of sarcomeres and the sarcoplasmic reticulum. FASEB $J$ 2006, 20(12):2102-2111.

62. Fan GC, Chu G, Kranias EG: Hsp20 and its cardioprotection. Trends Cardiovasc Med 2005, 15(4):138-141

63. Linke WA: Sense and stretchability: the role of titin and titin-associated proteins in myocardial stress-sensing and mechanical dysfunction. Cardiovasc Res 2008, 77(4):637-648.

64. Bos JM, Poley RN, Ny M, Tester DJ, Xu X, Vatta M, Towbin JA, Gersh BJ, Ommen SR, Ackerman MJ: Genotype-phenotype relationships involving hypertrophic cardiomyopathy-associated mutations in titin, muscle LIM protein, and telethonin. Mol Genet Metab 2006, 88(1):78-85.

65. Hayashi T, Arimura T, Itoh-Satoh M, Ueda K, Hohda S, Inagaki N, Takahashi $M$, Hori $H$, Yasunami $M$, Nishi $H$, et al: Tcap gene mutations in hypertrophic cardiomyopathy and dilated cardiomyopathy. J Am Coll Cardiol 2004, 44(11):2192-2201.

66. Nakagami H, Kikuchi Y, Katsuya T, Morishita R, Akasaka H, Saitoh S, Rakugi H, Kaneda Y, Shimamoto K, Ogihara T: Gene polymorphism of myospryn (cardiomyopathy-associated 5) is associated with left ventricular wall thickness in patients with hypertension. Hypertens Res 2007, 30(12):1239-1246. 
67. Benson MA, Tinsley CL, Blake DJ: Myospryn is a novel binding partner for dysbindin in muscle. J Biol Chem 2004, 279(11):10450-10458.

68. Graham IR, Hill VJ, Manoharan M, Inamati GB, Dickson G: Towards a therapeutic inhibition of dystrophin exon 23 splicing in $\mathrm{mdx}$ mouse muscle induced by antisense oligoribonucleotides (splicomers): target sequence optimisation using oligonucleotide arrays. J Gene Med 2004, 6(10):1149-1158.

69. Irizarry RA, Bolstad BM, Collin F, Cope LM, Hobbs B, Speed TP: Summaries of Affymetrix GeneChip probe level data. Nucleic Acids Res 2003, 31(4): e15.

70. Bolstad BM, Irizarry RA, Astrand M, Speed TP: A comparison of normalization methods for high density oligonucleotide array data based on variance and bias. Bioinformatics 2003, 19(2):185-193.

71. Du P, Kibbe WA, Lin SM: Iumi: a pipeline for processing Illumina microarray. Bioinformatics 2008, 24(13):1547-1548.

72. Smyth GK: Linear models and empirical bayes methods for assessing differential expression in microarray experiments. Stat Appl Genet Mol Biol 2004, 3, Article3.

73. Rozen S, Skaletsky H: Primer3 on the WWW for general users and for biologist programmers. Methods Mol Biol 2000, 132:365-386.

doi:10.1186/1471-2164-11-345

Cite this article as: Ghahramani Seno et al: Transcriptomic analysis of dystrophin RNAi knockdown reveals a central role for dystrophin in muscle differentiation and contractile apparatus organization. BMC Genomics 2010 11:345.

\section{Submit your next manuscript to BioMed Central} and take full advantage of:

- Convenient online submission

- Thorough peer review

- No space constraints or color figure charges

- Immediate publication on acceptance

- Inclusion in PubMed, CAS, Scopus and Google Scholar

- Research which is freely available for redistribution

Submit your manuscript at www.biomedcentral.com/submit 